\title{
Aplicação exógena de quitosana no sistema antioxidante de jaborandi
}

\author{
Exogenous chitosan application on antioxidant systems of jaborandi
}

\author{
Sara Dousseau ${ }^{\text {I }}$ Amanda Cristiane Rodrigues II Jean Marcel Sousa Lira ${ }^{\text {II }}$ \\ Pedro Martins Ribeiro Júnior ${ }^{\text {III }}$ Fernanda Ventorim Pacheco ${ }^{\text {II }}$ Amauri Alves de Alvarenga ${ }^{I I}$ \\ Mario Lúcio Vilela Resende ${ }^{\mathrm{IV}}$ Ana Cardoso Clemente Filha Ferreira de Paula
}

RESUMO

A aplicação de eliciadores em plantas é utilizada em estudos de fisiologia para compreensão dos mecanismos de defesa ao ataque de herbívoros ou infecção por patógenos. Em virtude disso, foi avaliado o efeito do eliciador exógeno quitosana no sistema antioxidante enzimático de jaborandi (Piper mollicomum Kunth). Foram avaliadas as atividades das enzimas ascorbato peroxidase (APX), catalase (CAT) e superóxido dismutase (SOD) e as concentrações de peróxido de hidrogênio $\left(\mathrm{H}_{2} \mathrm{O}_{2}\right)$ e malonaldeído (MDA), ambas análises para verificar a peroxidação lipídica. $O$ delineamento experimental utilizado foi o de blocos casualizados (DBC), constituido de um fatorial (5x2) composto pelos controles sem quitosana (plantas sem pulverização e plantas pulverizadas apenas com o solvente de diluição da quitosana) $e$ concentrações de quitosana (2,5; 5,0 e 10,0 $\left.\mathrm{g} \mathrm{L}^{-1}\right)$ em dois estádios de desenvolvimento foliar (em desenvolvimento e completamente expandida). Nas folhas completamente expandidas, o sistema antioxidante foi mais ativo. A CAT teve maior participação no sequestro de radicais livres, induzido pela aplicação da quitosana em ambos os estádios de desenvolvimento foliar. A APX foi induzida somente nas folhas completamente expandidas e na maior concentração de quitosana. O método do MDA foi melhor para evidenciar a diferença nos teores de peróxido de hidrogênio, em função do estresse induzido pela quitosana. De acordo com os resultados obtidos neste ensaio, pode-se sugerir que, nas plantas de jaborandi, as enzimas antioxidativas são requisitadas em resposta ao eliciador em questão, a quitosana, compondo, assim, o mecanismo de defesa dessas plantas.

Palavras-chave: eliciador quitosana, SOD, CAT, APX, Piper mollicomum.

\begin{abstract}
Elicitors are used in plant physiology studies for comprehension of defense mechanisms against herbivore attach and pathogen infections. For this reason, the exogenous chitosan effect was tested as an elicitor on Jaborandi (Piper mollicomum Kunth). Thus, it was evaluated the elicitor effect in the antioxidant enzymes superoxide dismutase (SOD), catalase (CAT), ascorbate peroxidase (APX), hydrogen peroxide $\left(\mathrm{H}_{2} \mathrm{O}_{2}\right)$ and malonaldehyde (MDA) concentrations to estimate the lipid peroxidation. The experimental design was in randomized blocks in a factorial $5 \times 2$, being 2 controls (plants without pulverization and plants sprayed only with a diluting solvent chitosan) and 3 chitosan concentrations $\left(2.5 ; 5.0\right.$ and $\left.10.0 \mathrm{~g} \mathrm{~L}^{-1}\right)$ in 2 leaf development stage (in development and fully expanded). At the fully expanded leaves, the antioxidant system presented higher active. The CAT had greater involvement in the kidnapping of free radicals induced by the application of chitosan in both leaf stages of development. The APX was induced only in fully expanded leaves and the highest concentration of chitosan. The MDA method was better to highlight the difference in hydrogen peroxide content as a function of stress induced by chitosan. According to the results of this test, it can be suggested that the plants Jaborandi antioxidant enzymes are required in response to the elicitor in question, chitosan, thus composing the defense mechanism of these plants.
\end{abstract}

Key words: chitosan elicitor, SOD, CAT, APX, Piper mollicomum.

\section{INTRODUÇÃO}

As plantas de Piper mollicomum Kunth (Piperaceae) são conhecidas popularmente como

\footnotetext{
'Centro Regional de Desenvolvimento Rural Centro Norte (CRDR-CN), Instituto Capixaba de Pesquisa, Assistência Técnica e Extensão Rural (INCAPER), BR 101 Norte, km 151, CP 62, 29915-140, Linhares, ES, Brasil. E-mail: saradousseau@yahoo.com.br. Autor para correspondência. IIDepartamento de Biologia, Setor de Fisiologia Vegetal, Universidade Federal de Lavras (UFLA), Lavras, MG, Brasil.

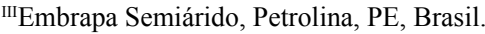

${ }^{\text {IV }}$ Departamento de Fitopatologia, UFLA, Lavras, MG, Brasil.

vDepartamento de Ciências Agrárias, Instituto Federal de Minas Gerais (IFMG), Bambuí, MG, Brasil.
} Recebido 10.08.13 Aprovado 18.05.15 Devolvido pelo autor 30.07.15 CR-2013-1332.R3 
jaborandi, possuemalto rendimento de óleos essenciais e diversas propriedades medicinais, destacando-se a atividade antimicrobiana (CORDOVA et al., 2010). Apesar das propriedades medicinais comprovadas, não é cultivada comercialmente e poucos trabalhos foram realizados abordando a produção dos compostos de interesse em condições de estresse.

Em resposta aos estresses bióticos, as plantas produzem diversos compostos de defesa, como as proteínas relacionadas à patogênese (STANGARLIN et al., 2011), que atuam diretamente no patógeno, liberando eliciadores não-específicos que podem ser reconhecidos pela própria planta, desencadeando respostas de defesa (VAN LOON et al., 2006). Nesse sentido, diversos compostos têm sido caracterizados como sinalizadores na resposta de defesa sistêmica, por mimetizarem o fenômeno de reconhecimento que ocorre na interação entre a planta e o patógeno (MEJÍA-TENIENTE et al., 2013). Dentre esses compostos, destaca-se a quitosana, um biopolímero hidrofílico constituído por moléculas de 2-amino2-deoxi-D-glicopiranose e 2-acetamido-2-deoxi-Dglicopiranose, unidas por ligações glicosídicas $\beta(1 \rightarrow 4)$ e obtidas através da desacetilação alcalina da quitina (RABEA et al., 2003).

Quando ocorre o reconhecimento do patógeno pela planta, aumenta a produção de espécies reativas de oxigênio (EROs) na célula vegetal como o íon superóxido $\left(\mathrm{O}_{2}^{-}\right)$e peróxido de hidrogênio $\left(\mathrm{H}_{2} \mathrm{O}_{2}\right)$ (SHARMA et al., 2012). Esta indução na formação das EROs também ocorrem quando as plantas reconhecem os compostos e liciadores como a quitosana (LEI et al., 2011).

As EROs em altas concentrações danificam o sistema de membranas, levando à peroxidação lipídica, culminando na morte celular, enquanto, em baixas concentrações, as $\mathrm{ERO}_{\mathrm{S}}$ atuam como moléculas sinalizadoras na expressão de genes ligados à defesa e respostas adaptativas, como síntese de lignina (BHATTACHARJEE, 2012; BARBOSA et al., 2014). A eliminação ou detoxificação das EROs em excesso é obtida por um complexo mecanismo de defesa das plantas, que envolve diversas enzimas e produção de substâncias sequestrantes desses radicais (SHARMA et al., 2012).

A possibilidade da utilização via aplicação exógena da quitosana, para a indução de metabólitos secundários, tem sido amplamente estudada na literatura, no entanto, ainda há carência e são necessários estudos para definir os tratamentos que induzam os compostos de interesse, sem acarretar dano celular (LEI et al., 2011). Sendo assim, a determinação da concentração de quitosana a ser aplicada é fundamental para que o metabolismo de defesa seja ativado, contudo, sem que haja a morte celular dessas plantas. Dessa forma, propôs-se avaliar com este trabalho qual seria a resposta do sistema antioxidante enzimático à aplicação de diferentes concentrações do eliciador exógeno quitosana em folhas jovens e completamente expandidas de Piper mollicomum Kunth, com o objetivo de definir a concentração de quitosana que possa ser utilizada na indução de metabólitos de interesse.

\section{MATERIAL E MÉTODOS}

Para obtenção das mudas de $\boldsymbol{P}$. mollicomum, sementes foram pré-germinadas em placas de Petri sobre três folhas de papel de filtro umedecidas e mantidas em câmara de germinação do tipo Mangesdorf (Marconi) a $25^{\circ} \mathrm{C}$, por 30 dias. Após esse período, as plântulas foram transferidas para bandejas de polipropileno expandido de 72 células, contendo substrato organomineral (Plantmax ${ }^{\circledR}$ ), e mantidas por 60 dias em sala de crescimento com fotoperíodo de $12 \mathrm{~h}$, controlado por temporizador digital (FoxLux), com radiação incidente de $300 \mu \mathrm{mol}$ de quanta $\mathrm{m}^{-2} \mathrm{~s}^{-1}$, medida através do LI190SB Quantum Sensor (LI-COR's). A umidade relativa foi mantida a $60 \%$ e a temperatura de $25 \pm 2^{\circ} \mathrm{C}$, mensuradas com o auxílio do termohigrômetro digital (THO2-IMPAC). Após esse período, as mudas foram transplantadas para vasos com capacidade de 6L, contendo terra de subsolo, areia e composto orgânico, na proporção de 2:1:1 e mantidas durante 4 meses em condições de viveiro, construído com telas pretas padrão para promover $50 \%$ de sombreamento e altura do pé-direito de $3 \mathrm{~m}$. Os tratamentos foram conduzidos no estádio de florescência das plantas de jaborandi.

As concentrações de quitosana utilizadas nos ensaios foram de 2,5; 5 e $10 \mathrm{~g} \mathrm{~L}^{-1}$, cujas soluções foram preparadas pela dissolução do eliciador em ácido clorídrico a $0,05 \mathrm{~N}$ sob agitação constante e correção do $\mathrm{pH}$ para 5,5, com hidróxido de sódio (Di PIERO \& GARDA, 2008). O padrão de quitosana utilizado foi o de baixo peso molecular, contendo $75-85 \%$ de desacetilação (Sigma-Aldrich) (448869-250G). Como controle, foram utilizadas plantas não pulverizadas e plantas pulverizadas apenas com solução de ácido clorídrico a $0,05 \mathrm{~N}$, com o $\mathrm{pH}$ da solução corrigido para 5,5, com hidróxido de sódio. Em cada planta, foram pulverizadas $200 \mathrm{~mL}$ das soluções.

Vinte e quatro horas após a pulverização, foram avaliadas três plantas de cada tratamento. De cada planta, foram coletadas uma amostra da folha em desenvolvimento (inserida no segundo nó a partir do ápice) e outra da completamente expandida (inserida 
no terceiro ou quarto nó). Essa coleta foi efetuada em um único dia, entre 8 e $10 \mathrm{~h}$, e o procedimento foi realizado com auxílio de uma tesoura, coletandose apenas os fragmentos da região mediana do limbo foliar (descartando-se a nervura central e as bordas) e imediatamente acondicionando-os em tubos falcon e congelando em nitrogênio líquido, para que fosse armazenado em ultrafreezer a $-86^{\circ} \mathrm{C}$, até o momento do preparo dos extratos.

Os extratos para quantificação da atividade das enzimas foram obtidos através da maceração a frio com auxílio de almofariz. Cerca de $0,07 \mathrm{~g}$ de tecido foliar foi submetido a extração em solução contendo $100 \mathrm{mM}$ de tampão fosfato de potássio $(\mathrm{pH}$ $7,8), 0,1 \mathrm{mM}$ de EDTA e $10 \mathrm{mM}$ de ácido ascórbico, perfazendo um volume de $1,5 \mathrm{~mL}$. O extrato foi centrifugado a $13000 \mathrm{xg}$ por 10 minutos a $4^{\circ} \mathrm{C}$. O sobrenadante coletado foi utilizado nos ensaios enzimáticos. Essa extração foi realizada segundo metodologia de BIEMELT et al. (1998). Para a determinação da atividade específica das enzimas, foi realizada a quantificação de proteínas solúveis de cada extrato enzimático (BRADFORD, 1976).

A atividade da SOD foi avaliada pela capacidade da enzima em inibir a fotorredução do azul de nitrotetrazólio (NBT), conforme proposto por GIANNOPOLITIS \& RIES (1977), com modificações. Foram adicionados $10 \mu \mathrm{L}$ do extrato enzimático a $190 \mu \mathrm{L}$ do meio de reação composto por: tampão de fosfato de potássio $50 \mathrm{mM}(\mathrm{pH} 7,8)$, metionina $14 \mathrm{mM}$, EDTA $0,1 \mu \mathrm{M}$, NBT $75 \mu \mathrm{M}$ e riboflavina $2 \mu \mathrm{M}$. $\mathrm{O}$ meio de reação mais a amostra foram iluminados com lâmpada fluorescente de $15 \mathrm{~W}$ por 10 minutos. As leituras de absorbância foram realizadas a $560 \mathrm{~nm}$ em espectrofotômetro (EPOCH-BIOTECK-ELISA). Uma unidade de SOD foi definida como a quantidade necessária da enzima para inibir em $50 \%$ a fotorredução do NBT nas condições do ensaio.

A atividade da catalase (CAT) foi obtida segundo HAVIR \& McHALE (1987). Alíquotas de $10 \mu \mathrm{L}$ do extrato enzimático foram adicionados a $190 \mu \mathrm{L}$ do meio de reação, contendo $100 \mu \mathrm{L}$ de fosfato de potássio $200 \mathrm{mM}$ ( $\mathrm{pH} 7,0$ ) e $10 \mu \mathrm{L}$ de peróxido de hidrogênio $12,5 \mathrm{mM}$ e $80 \mu \mathrm{L}$ de água destilada incubado a $28^{\circ} \mathrm{C}$. A atividade dessa enzima foi determinada em espectrofotômetro (EPOCH-BIOTECK-ELISA), pela redução da absorbância a $240 \mathrm{~nm}$, a cada 15 segundos, por 3 minutos, monitorado pelo consumo de peróxido de hidrogênio. Uma unidade da atividade da CAT foi definida como a degradação de $1 \mu \mathrm{M}$ de $\mathrm{H}_{2} \mathrm{O}_{2}$ durante um minuto. O coeficiente de extinção molar $(\varepsilon)$ utilizado nos cálculos para esta enzima foi $36 \mathrm{mM}^{-1} \mathrm{~cm}^{-1}$.

A atividade do ascorbato peroxidase (APX) foi obtida de acordo com NAKANO \& ASADA
(1981). Para a medida de atividade, foi utilizado $10 \mu \mathrm{L}$ de extrato adicionado de $190 \mu \mathrm{L}$ de tampão de incubação, composto por $100 \mu \mathrm{L}$ de tampão fosfato de potássio $200 \mathrm{mM}(\mathrm{pH} 7,0), 10 \mu \mathrm{L}$ de ácido ascórbico $10 \mathrm{mM}, 10 \mu \mathrm{L}$ de peróxido de hidrogênio $2 \mathrm{mM}$ e $70 \mu \mathrm{L}$ de água destilada. A atividade dessa enzima foi determinada pelo acompanhamento da oxidação do ascorbato, a cada 15 segundos, durante 3 minutos. A reação oxidativa foi monitorada através das medidas espectrofotométricas a 290nm. Uma unidade da atividade da APX foi definida como a conversão de $1 \mu \mathrm{M}$ de ácido ascórbico em monodehidroascorbato durante um minuto. $\mathrm{O} \varepsilon$ utilizado nos cálculos para esta enzima foi $2,8 \mathrm{mM}^{-1} \mathrm{~cm}^{-1}$.

A concentração de $\mathrm{H}_{2} \mathrm{O}_{2}$ foi determinada através da metodologia descrita por ALEXIEVA et al. (2001). Cerca de 0,02g de material congelado foi macerado e extraído em solução ácida composta por $5 \mathrm{~mL}$ de TCA (ácido tricloroacético- SYNTH) a $0,1 \%$ $(\mathrm{m} / \mathrm{v})$ e centrifugados a $12000 x g$ por 15 minutos, a $4^{\circ} \mathrm{C}$. Para quantificação de peróxido, foi utilizada uma alíquota de $10 \mu \mathrm{L}$ do extrato adicionado de $40 \mu \mathrm{L}$ de TCA $0,1 \%, 50 \mu \mathrm{L}$ de tampão de fosfato de potássio $(\mathrm{pH} 7,0) 100 \mathrm{mM}$ e $100 \mu \mathrm{L}$ de iodeto de potássio $1 \mathrm{M}$. As leituras de absorbância foram realizadas a 390nm. $\mathrm{O}$ conteúdo de $\mathrm{H}_{2} \mathrm{O}_{2}$ foi calculado comparando as leituras com as obtidas através de uma curva padrão de peróxido de hidrogênio $\left(\mathrm{H}_{2} \mathrm{O}_{2}\right)$.

Para a avaliação dos possíveis danos celulares desencadeados pelas doses da quitosana, foi medida a quantidade de peróxidos totais liberada pela peroxidação lipídica. Para tanto, essa peroxidação foi determinada pela quantificação das espécies reativas ao ácido tiobarbitúrico (TBARS), como descrito por KRAMER et al. (1991). Foi macerado cerca de 0,02g com $5 \mathrm{~mL}$ de TCA $0,1 \%$. O homogeneizado foi então centrifugado a $10000 \mathrm{xg}$ por 10 minutos a $4^{\circ} \mathrm{C}$. Alíquotas de $10 \mu \mathrm{L}$ do sobrenadante foram adicionados a $190 \mu \mathrm{L}$ do meio de reação composto por ácido tiobarbitúrico (TBA) $0,5 \%(\mathrm{~m} / \mathrm{v})$ e TCA $10 \%(\mathrm{~m} / \mathrm{v})$ e incubados a $95^{\circ} \mathrm{C}$ por 30 minutos. A reação foi interrompida pelo rápido resfriamento em banho de gelo. A absorbância foi determinada a $532 \mathrm{~nm}$ e, para se obter os valores de absorbância líquida, este valor foi descontado da absorbância inespecífica a $600 \mathrm{~nm}$. Os cálculos relativos à liberação de peróxidos através do MDA foram realizados de acordo com a equação $\{[($ A532-A600)/157000] 106\} e expressos em nmol $\mathrm{mL}^{-1}$.

O delineamento experimental utilizado foi o de blocos casualizados com três repetições e uma planta por parcela. Os dados obtidos foram submetidos ao teste de normalidade (Shapiro-Wilk), à análise de variância paramétrica (ANOVA) e ao teste 
de Scott-Knott $(\mathrm{P}<0,05)$, utilizando-se o programa SISVAR, versão 4.3 (FERREIRA, 1999).

\section{RESULTADOS E DISCUSSÃO}

Para todas as variáveis analisadas não foi observada interação significativa para os fatores estudados, demonstrando que eles atuaram de maneira independente (Tabela 1). Foi observado aumento na atividade da APX em relação as plantas que não foram elicitadas, demonstrando que o efeito não deve ser da quitosana, mas sim do estresse promovido pelo solvente ácido utilizado. No entanto, através da análise do erro padrão da média, pode ser observado que, nas folhas completamente expandidas, a maior concentração de quitosana promoveu aumento na atividade da APX procedente da indução do estresse promovido pela aplicação do eliciador. Contudo, nas folhas em desenvolvimento, a atividade da APX foi inferior, quando se utiliza a quitosana nas concentrações de 5 e $10 \mathrm{~g} \mathrm{~L}^{-1}$.

$\mathrm{O}$ aumento na atividade da APX já em função da aplicação da solução ácida pode ser explicado pela sua elevada afinidade pelo $\mathrm{H}_{2} \mathrm{O}_{2}$, o que a torna muito útil para uma regulação metabólica fina, devido a sua capacidade de eliminar baixas concentrações desse radical livre (BARBOSA et al., 2014). A APX é uma das enzimas antioxidantes mais amplamente distribuídas em células de plantas e, devido à maior afinidade pelo substrato peróxido com relação à CAT, é considerada uma eficiente sequestradora dessa espécie reativa em condições de estresse (SHARMA et al., 2012). Corroborando os resultados observados para a dose de $10 \mathrm{~g} \mathrm{~L}^{-1}$, LEI et al. (2011) verificaram que o tratamento com quitosana promoveu aumento na atividade da APX.

Tabela 1 - Atividade das enzimas peroxidase do ascorbato (APX), catalase (CAT) e superóxido dismutase (SOD) e teores de peróxido de hidrogênio $\left(\mathrm{H}_{2} \mathrm{O}_{2}\right)$ e melonaldeído (peroxidação lipídica). Análise em folhas em desenvolvimento (ED) e completamente expandidas (CE) de jaborandi (P. mollicomum), submetidos aos seguintes tratamentos: sem aplicação de nenhum composto (sem elicitar), com aplicação do ácido clorídrico a $0,05 \mathrm{~N}$ (solvente) e com aplicação de quitosana nas concentrações de 2,$5 ; 5$ e $10 \mathrm{~g} \mathrm{~L}^{-1}$.

\begin{tabular}{|c|c|c|c|c|c|c|}
\hline \multirow{2}{*}{$\begin{array}{l}\text { Estádio } \\
\text { foliar }\end{array}$} & \multicolumn{2}{|c|}{---------------- Controles -----------------. } & \multicolumn{3}{|c|}{ 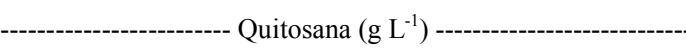 } & \multirow{2}{*}{ Média } \\
\hline & Sem elicitar & Solvente & 2,5 & 5 & 10 & \\
\hline ED & $0,35 \pm 0,12$ & $0,53 \pm 0,03$ & $0,58 \pm 0,01$ & $0,40 \pm 0,04$ & $0,47 \pm 0,01$ & $0,47 \mathrm{~B}$ \\
\hline $\mathrm{CE}$ & $0,43 \pm 0,08$ & $0,66 \pm 0,07$ & $0,61 \pm 0,05$ & $0,66 \pm 0,05$ & $0,82 \pm 0,06$ & $0,63 \mathrm{~A}$ \\
\hline Média & $0,39 \mathrm{~b}$ & $0,59 \mathrm{a}$ & $0,60 \mathrm{a}$ & $0,53 \mathrm{a}$ & $0,64 \mathrm{a}$ & \\
\hline \multirow[t]{2}{*}{$\mathrm{CV}(\%)$} & \multicolumn{6}{|c|}{19,53} \\
\hline & 更 & Atividade da $\mathrm{CA}$ & $\mu \mathrm{mol} \mathrm{de} \mathrm{H}_{2} \mathrm{O}_{2} \cdot \mathrm{mi}$ & $\mathrm{ng}^{-1}$ de proteína) & 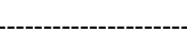 & \\
\hline ED & $0,0125 \pm 0,0037$ & $0,0067 \pm 0,0020$ & $0,0061 \pm 0,0023$ & $0,0031 \pm 0,0021$ & $0,0185 \pm 0,0032$ & 0,0094 \\
\hline $\mathrm{CE}$ & $0,0069 \pm 0,0014$ & $0,0058+0,0012$ & $0,007 \pm 0,0023$ & $0,0099 \pm 0,0024$ & $0,0112+0,0019$ & 0,0082 \\
\hline Média & $0,0097 \mathrm{~b}$ & $0,0063 \mathrm{~b}$ & $0,0065 \mathrm{~b}$ & $0,0065 \mathrm{~b}$ & $0,0149 \mathrm{a}$ & \\
\hline \multirow{2}{*}{$\mathrm{CV}(\%)$} & \multicolumn{6}{|c|}{46,02} \\
\hline & ----------------. & --- Atividade da & (U em $\mu$ mol.g ${ }^{-1}$ & $\mathrm{mg}^{-1}$ de proteína & --------------------' & -------. \\
\hline ED & $1,89 \pm 0,09$ & $2,23 \pm 0,04$ & $2,6 \pm 0,08$ & $2,38+0,11$ & $2,16 \pm 0,01$ & $2,25 \mathrm{~B}$ \\
\hline $\mathrm{CE}$ & $2,71 \pm 0,49$ & $2,9 \pm 0,32$ & $2,78 \pm 0,04$ & $3,41 \pm 0,16$ & $2,59 \pm 0,15$ & $2,88 \mathrm{~A}$ \\
\hline Média & 2,3 & 2,56 & 2,69 & 2,9 & 2,38 & \\
\hline \multirow[t]{2}{*}{$\mathrm{CV}(\%)$} & \multicolumn{6}{|c|}{14,24} \\
\hline & & 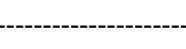 & or de $\mathrm{H}_{2} \mathrm{O}_{2}(\mu \mathrm{g} \cdot \mathrm{g}$ & 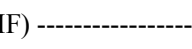 & - & 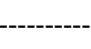 \\
\hline ED & $0,56 \pm 0,08$ & $0,71 \pm 0,08$ & $0,56 \pm 0,08$ & $0,37 \pm 0,04$ & $0,24 \pm 0,05$ & $0,48 \mathrm{~B}$ \\
\hline $\mathrm{CE}$ & $0,76 \pm 0,06$ & $1,09 \pm 0,26$ & $1,04 \pm 0,15$ & $0,78 \pm 0,18$ & $1,17 \pm 0,17$ & $0,97 \mathrm{~A}$ \\
\hline Média & 0,66 & 0,9 & 0,8 & 0,57 & 0,71 & \\
\hline \multirow[t]{2}{*}{$\mathrm{CV}(\%)$} & \multicolumn{6}{|c|}{29,81} \\
\hline & - & ----- Peroxid & lipídica $(\mu \mathrm{mol} \mathrm{c}$ & [DA.g ${ }^{-1}$ MF) --.-. & -------------. & \\
\hline ED & $0,11 \pm 0,02$ & $0,18 \pm 0,04$ & $0,21 \pm 0,02$ & $0,16 \pm 0,004$ & $0,12 \pm 0,03$ & $0,16 \mathrm{~B}$ \\
\hline $\mathrm{CE}$ & $0,71 \pm 0,16$ & $0,67 \pm 0,07$ & $0,48 \pm 0,07$ & $0,65 \pm 0,08$ & $1,05 \pm 0,03$ & $0,71 \mathrm{~A}$ \\
\hline Média & $0,41 \mathrm{~b}$ & $0,43 \mathrm{~b}$ & $0,34 \mathrm{~b}$ & $0,41 \mathrm{~b}$ & $0,58 \mathrm{a}$ & \\
\hline $\mathrm{CV}(\%)$ & \multicolumn{6}{|c|}{23,38} \\
\hline
\end{tabular}

Médias seguidas pelas mesmas letras minúsculas nas linhas e maiúsculas nas colunas não diferem entre si, pelo teste de $\mathrm{Scott}-\mathrm{Knot}$ ( $\mathrm{P}<0,05)$. Os valores do interior da tabela são expressos como média \pm erro padrão da média. As médias externas correspondem às médias dos fatores independentes. 
A atividade da CAT foi aumentada pela aplicação de quitosana na concentração de $10 \mathrm{~g} \mathrm{~L}^{-1}$, independentemente do estádio de desenvolvimento foliar (Tabela 1). Entretanto, quando se analisa o erro padrão da média, pode ser observado que, nas folhas completamente expandidas, a aplicação de quitosana na concentração de $5 \mathrm{~g} \mathrm{~L}^{-1}$ já foi suficiente para promover aumento na atividade da CAT, enquanto, nas folhas em desenvolvimento, somente a maior concentração proporcionou aumento na atividade desta enzima.

De acordo com os resultados obtidos neste ensaio, podemos concluir que a CAT teve maior participação no sequestro de radicais livres por ter sido induzida pela aplicação da quitosana já na concentração mediana, embora para outras espécies vegetais. Esta enzima somente é ativada sob condições de estresse elevado (BARBOSA et al., 2014), que, de acordo com NOCTOR \& FOYER (1998), é devido à baixa afinidade desta enzima pelo $\mathrm{H}_{2} \mathrm{O}_{2}$ e à alta velocidade de reação. Diversos trabalhos estão de acordo com os resultados do presente estudo, nos quais o tratamento com quitosana também promoveu aumento na atividade da CAT (MANDAL, 2010; LEI et al., 2011; ZENG \& LUO, 2012; MEJÍATENIENTE et al., 2013).

Através da análise de variância, não foram observadas diferenças significativas na atividade da SOD e no teor de $\mathrm{H}_{2} \mathrm{O}_{2}$, no entanto, diferenças foram identificadas pelo erro padrão da média (Tabela 1). Nas folhas em desenvolvimento, a aplicação de quitosana nas concentrações de 2,5 e 5 foi capaz de promover aumento na atividade da SOD, enquanto, nas folhas completamente expandidas, este efeito somente foi observado na concentração de $5 \mathrm{~g} \mathrm{~L}^{-1}$.

A SOD catalisa a dismutação do $\mathrm{O}_{2}^{-}$a oxigênio com a formação de $\mathrm{H}_{2} \mathrm{O}_{2}$ e o aumento na atividade desta enzima é geralmente correlacionado com a elevação nos níveis de radicais livres (KARUPPANAPANDIAN et al. 2011; SHARMA et al., 2012). O aumento na atividade da SOD, promovido pela aplicação de quitosana, vem sendo observada em alguns trabalhos, corroborando os resultados obtidos neste ensaio (FAN et al. 2010; LEI et al., 2011).

Como não foi observado aumento no teor de $\mathrm{H}_{2} \mathrm{O}_{2}$, em função da aplicação de quitosana, poderia ser um indicativo de que este eliciador não influenciou na produção dessa espécie reativa. No entanto, as enzimas APX e a CAT foram ativadas pela quitosana e, sendo $\mathrm{O}_{2} \mathrm{O}_{2}$ substrato para ambas as enzimas, provavelmente outras fontes, que não a atividade da SOD, estão contribuindo para a liberação de $\mathrm{H}_{2} \mathrm{O}_{2}$. Segundo Lei et al. (2011), a quitosana promove maior aumento no anião superóxido, em relação ao peróxido de hidrogênio, principalmente nas primeiras horas após a eliciação. Como tem sido extensivamente documentado que diversas reações metabólicas originam $\mathrm{O} \quad \mathrm{H}_{2} \mathrm{O}_{2}$, inclusive espontaneamente, pode-se considerar que, nas folhas de jaborandi, a atividade da SOD não foi indicadora da presença de peróxidos (KARUPPANAPANDIAN et al. 2011; BHATTACHARJEE, 2012; BARBOSA et al., 2014).

Através da análise de médias, pode ser observado que a aplicação de quitosana na maior concentração promoveu aumento na peroxidação lipídica, indicando que a análise por MDA, na qual se faz a análise específica de peróxido, foi muito melhor e deixou evidente a diferença nos teores de peróxido de hidrogênio, corroborando o efeito na atividade das enzimas antioxidantes avaliadas (Tabela 1). Quando se analisa o erro padrão da média, pode ser observado que o aumeto na peroxidação lipídica somente ocorreu nas folhas completamente expandidas.

O aumento na concentração de peróxidos, concomitante à ativação da CAT, sugere a hipótese de que o tratamento na maior concentração de quitosana induziu de forma elevada o estresse oxidativo das células do jaborandi. Supõem-se que, na maior concentração de quitosana aplicada, a produção de espécies reativas de oxigênio excedeu a capacidade de controle da célula, acarretando em dano por peroxidação lipídica, oxidação de proteínas, danos para os ácidos nucleicos e inibição de enzimas (SHARMA et al., 2012). De fato, isso foi observado na maior concentração que as folhas completamente expandidas apresentaram o bordo necrosado e inúmeros pontos necróticos no limbo, vindo a sofrer abscisão com o decorrer dos dias.

Embora não tenha sido observada interação entre o estádio de desenvolvimento da folha e a aplicação de quitosana, pode ser evidenciado que, nas folhas completamente expandidas, todo o metabolismo antioxidante é mais ativo, refletindo em uma maior atividade da SOD, do teor de $\mathrm{H}_{2} \mathrm{O}_{2}$ e peroxidação lipídica. Este aumento pode ser explicado pelo maior desenvolvimento foliar, o que leva a uma maior taxa respiratória, consequentemente, uma maior atividade do sistema antioxidante para manter a homeostase (SIMÃO et al., 2013).

\section{CONCLUSÃO}

A quitosana foi um eliciador que, nas doses adequadas, ativou de maneira eficiente o sistema antioxidante nas folhas de jaborandi. A CAT teve maior participação no sequestro de radicais livres, induzido pela aplicação da quitosana, enquanto a 
APX foi induzida somente nas folhas completamente expandidas e na maior concentração de quitosana. A análise específica do peróxido de hidrogênio, realizada pelo metodo do MDA, foi melhor e evidenciou a diferença nos teores de peróxido de hidrogênio. Nas folhas completamente expandidas, o sistema antioxidante é mais ativo.

\section{AGRADECIMENTOS}

Ao Conselho Nacional de Desenvolvimento Científico e Tecnológico $(\mathrm{CNPq})$, pela bolsa de Doutorado destinada a primeira autora e a Fundação de Amparo à Pesquisa do Estado de Minas Gerais (FAPEMIG) pelo auxílio financeiro.

\section{REFERÊNCIAS}

ALEXIEVA, V. et al. The effect of drought and ultraviolet radiation on growth and stress markers in pea and wheat. Plant Cell and Environment, Oxford, v.24, n.12, p.1337-1344, 2001. Disponível $\mathrm{em}$ : <http://onlinelibrary.wiley.com $>$. Acesso: 14 maio 2012. doi: 10.1046/j.1365-3040.2001.00778.x.

BARBOSA, M.R. et al. Geração e desintoxicação enzimática de espécies reativas de oxigênio em plantas. Ciência Rural, Santa Maria, v.44, n.3, p.453-460, 2014. Disponível em: <http://www. scielo.br/pdf/cr/v44n3/a7914cr2013-0032.pdf >. Acesso: 9 abr. 2014. doi: 10.1590/S0103-84782014000300011.

BHATTACHARJEE, S. The language of reactive oxygen species signaling in plants. Journal of Botany, London, v.12, p.1-22, 2012. Disponível em: <http://www.hindawi. com/journals/jb/2012/985298/>. Acesso: 21 jun. 2012. doi: $10.1155 / 2012 / 985298$.

BIEMELT, S. et al. Re-Aeration following hypoxia or anoxia leads to activation of the antioxidative defense system in roots of wheat seedlings. Plant Physiology, Washington, v.116, p.651658, 1998. Disponível em: <http://www.plantphysiology.org/ content/116/2/651.short>. Acesso: 25 ago. 2012. doi: 10.1104/ pp.116.2.651.

BRADFORD, M.M. A rapid and sensitive method for the quantitation of microgram quantities of protein utilizing the principle of protein-dye binding. Analytical Biochemistry, New York, v.72, n.2, p.248-254, 1976. Disponível em: <http:// www.sciencedirect.com/science/article/pii/0003269776905273>. Acesso: 12 jan. 2012 doi: 10.1016/0003-2697(76)90527-3.

CORDOVA, S.M. de et al. Análise da atividade antimicrobiana de extratos isolados de plantas nativas da flora brasileira frente a Mycoplasma arginini, M. hominis e Ureaplasma urealyticum. Revista Brasileira de Análises Clínicas, Rio de Janeiro, v.42, n.4, p.241-244, 2010. Disponível em: <http://www.sbac.org.br/pt/pdfs/ rbac/rbac_42_04/rbac_42_04_02.pdf $>$. Acesso: 21 mar. 2012.

DI PIERO, R.M.; GARDA, M.V. Quitosana reduz a severidade da antracnose e aumenta a atividade de glucanase em feijoeirocomum. Pesquisa Agropecuária Brasileira, Brasília, v.43, n.9, p.1121-1128, 2008. Disponível em: <http://www.scielo.br/pdf/pab/ v43n9/04.pdf>. Acesso: 22 mar. 2012.

FAN, G. et al. Chitosan activates defense responses and triterpenoid production in cell suspension cultures of Betula platyphylla Suk.
African Journal of Biotechnology, Kenya, v.9, n.19, p.28162820, 2010. Disponível em: <http://www.academicjournals.org/ $\mathrm{AJb} / \mathrm{PDF} / \mathrm{pdf} 2010 / 10 \mathrm{May} / \mathrm{Fan} \% 20 \mathrm{et} \% 20 \mathrm{al} . \mathrm{pdf}>$. Acesso: 25 maio 2012. doi: $10.5897 /$ AJB09.1975.

FERREIRA, D.F. Sistema de análises estatísticas 4.3. Lavras: UFLA, 1999. Disponível em: <http://www.dex.ufla.br/ danielff/ sisvarmanual.pdf>. Acesso: 18 jan. 2010.

GIANNOPOLITIS, C.N.; RIES, S.K. Superoxide dismutases I. Occurrence in higher plants. Plant Physiology, Washington, v.59, n.2, p.309-314, 1977. Disponível em: <http://www.plantphysiol. org/content/59/2/309.full.pdf+html $>$. Acesso: 14 fev. 2012. doi: 0.1104/pp.59.2.309.

HAVIR, E.A.; MCHALE, N.A. Biochemical and developmental characterization of multiple forms of catalase in tobacco leaves. Plant Physiology, Washington, v.67, n.3, p.450-455, 1987. Disponível em: <http://www.plantphysiol.org/content/84/2/450. short>. Acesso: 13 nov. 2011. doi: 10.1104/pp.84.2.450.

KARUPPANAPANDIAN, T. et al. Reactive oxygen species in plants: their generation, signal transduction, and scavenging mechanisms. Australian Journal of Crop Science, Boston, v.5, n.6, p.709-725, 2011. Disponível em: <http:/www.cropj.com/ kim_5_6_2011_709_725.pdf>. Acesso em: $23 \mathrm{dez} .2011$.

KRAMER, G.F. et al. Influence of UV-B radiation on polyamines, lipid peroxidation and membrane lipids in cucumber. Phytochemistry, v.30, n.7, p.2101-2108, 1991. Disponível em: $<$ http://www.sciencedirect.com/science/article/ pii/003194229183595C > . Acesso: 21 out 2011. doi: 10.1016/00319422(91)83595-C.

LEI, C. et al. Foliar application of chitosan activates artemisinin biosynthesis in Artemisia annua L. Industrial Crops and Products, Oxford, v.33, n.1, p.176-182, 2011. Disponível em: <http://www. sciencedirect.com/science/article/pii/S0926669010002463>. Acesso: 22 set. 2012. doi: 10.1016/j.indcrop.2010.10.001.

MANDAL, S. Induction of phenolics, lignin and key defense enzymes in eggplant (Solanum melongena L.) roots in response to elicitors. African Journal of Biotechnology, Kenya, v.9, n.47, p.8038-8047,2010. Disponível em: $<$ http://www.academicjournals. org/ajb/pdf/pdf2010/22Nov/Mandal.pdf>. Acesso: 20 abr. 2012. doi: $10.5897 /$ AJB10.984.

MEJÍA-TENIENTE, L. et al. Oxidative and molecular responses in Capsicum annuum L. after hydrogen peroxide, salicylic acid and chitosan foliar applications. International Journal of Molecular Sciences, Basel, Switzerland, v.14, n.5, p.1017810196, 2013. Disponível em: <http://www.ncbi.nlm.nih.gov/pmc/ articles/PMC3676835/>. Acesso: 26 dez. 2013. doi: 10.3390/ ijms 140510178 .

NAKANO, Y.; ASADA, K. Hydrogen peroxide is scavenged by ascorbate-specific peroxidase in spinach chloroplasts. Plant and Cell Physiology, Oxford, v.22, n.5, p.867-880, 1981. Disponível em: $<$ http:// pcp.oxfordjournals.org/content/22/5/867.short>. Acesso: 16 mar. 2012.

NOCTOR, G.; FOYER, C.H. Simultaneous measurement of foliar glutathione, $\gamma$-glutamylcysteyne, and amino acids by highperformance liquid chromatography: comparison with two other assay methods for glutathione. Analytical Biochemistry, New York, v.264, n.3, p.98-110, 1998. Disponível em: <http://www. 
sciencedirect.com/science/article/pii/S0003269798927944>. Acesso: 23 nov. 2011. doi: 10.1006/abio.1998.2794.

RABEA, E.I. et al. Chitosan as antimicrobial agent: applications and mode of action. Biomacromolecules, Washington, v.4, n.3, p.1457-1465, 2003. Disponível em: <http://pubs.acs.org/doi/ abs/10.1021/bm034130m > . Acesso: 6 dez. 2011. doi: 10.1021/ bm034130m.

SHARMA, P. et al. Reactive oxygen species, oxidative damage, and antioxidative defense mechanism in plants under stressful conditions. Journal of Botany, London, v.2012, p.1-26, 2012. Disponível em: <http://www.hindawi. com/journals/jb/2012/217037/abs/>. Acesso: jun. 2012. doi: $10.1155 / 2012 / 217037$

SIMÃO, A.A. et al. Antioxidants and chlorophyll in cassava leaves at three plant ages. African Journal of Agricultural Research, Nairobi, v.8, p.3724-3730, 2013. Disponível em: <http://www.
academicjournals.org/AJAR> Acesso: 20 ago. 2013. doi: 10.5897/ AJAR2013.6746.

STANGARLIN, J.R. et al. A defesa vegetal contra fitopatógenos. Scientia Agraria Paranaenis, Paraná, v.10, n.1, p18-46, 2011. Disponível em: <http://e-revista.unioeste.br/index.php/ scientiaagraria/article/view/5268>. Acesso: 10 jun. 2013.

VAN LOON, L.C. et al. Significance of inducible defense-related proteins in infected plants. Annual Review of Phytopathology, Palo Alto, v.44,p.135-62.2006. Disponívelem: $<$ http://www.annualreviews. org/doi/abs/10.1146/annurev.phyto.44.070505.143425>. Acesso: 23 out. 2012. doi: 10.1146/annurev.phyto.44.070505.143425.

ZENG, D.; LUO, X. Physiological effects of chitosan coating on wheat growth and activities of protective enzyme with drought tolerance. Open Journal of Soil Science, Wuhan, v.2, n.3, p.282288, 2012. Disponível em: <http://www.SciRP.org/journal/ojss>. Acesso: 23 out. 2012. doi: 10.4236/ojss.2012.23034. 